\title{
HUBUNGAN ANTARA PERSEPSI ATLET WUSHU SANDA SENIOR PADA PROGRAM LATIHAN DENGAN MOTIVASI BERPRESTASI DALAM MENGHADAPI PEKAN OLAHRAGA PROVINSI (PORPROV) TAHUN 2019
}

\author{
Muhammad Anis Zawawi \\ Penjaskesrek UN PGRI Kediri \\ E-mail: zawawi@unpkediri.ac.id \\ Diterima: 16 Mei 2018; Lolos: 30 Mei 2018; Dipublikasikan: 31 Mei 2018 \\ DOI: https://doi.org/10.29407/js_unpgri.v4i1.12116
}

\begin{abstract}
Abstrak
Tujuan dari penelitian ini adalah untuk mengetahui hubungan antara persepsi atlet wushu senior pada program latihan dengan motivasi berprestasi dalam menghadapi Pekan Olahraga Provinsi (PORPROV) tahun 2019. Penelitian ini menggunakan studi populasi pada atlet wushu yang tergabung di Puslatkot di Kota Kediri dengan jumlah atlet 14 orang yang terdiri dari 6 atlet putri dan 8 atlet putra. Instrumen pengumpulan data yang digunakan adalah skala persepsi atlet wushu senior pada program latihan dengan nilai validitas sebesar $0,302-0,886$ serta reliabilitas 0,949 serta skala motivasi berprestasi dengan nilai validitas sebesar $0,452-0,873$ serta reliabilitas 0,962 . Analisis data menggunakan teknik korelasi Product Moment Pearson. Berdasarkan analisis data yang dilakukan dengan menggunakan uji korelasi product moment, diperoleh nilai koefisien korelasi $(r)$ sebesar 0,$477 ; p=0,000(p<0,05)$ artinya ada hubungan yang positif dan signifikan antara persepsi atlet wushu senior pada program latihan dengan motivasi berprestasi pada atlet wushu senior.
\end{abstract}

Kata kunci: Persepsi pada program latihan, motivasi berprestasi, atlet wushu.

\section{CORRELATION BETWEEN THE PERCEPTION OF ATLET WUSHU SANDA SENIOR IN THE EXERCISE PROGRAM WITH ACHIEVEMENT MOTIVATION IN THE FACE OF PROVINCIAL SPORT WEEK (PORPROV) IN 2019}

\begin{abstract}
The purpose of this study was to determine the relationship between the perception of senior wushu athletes in the exercise program with achievement motivation in the face of Provincial Sports Week (PORPROV) in 2019. This study uses population studies on wushu athletes who are incorporated in Puslatkot in Kediri City with the number of athletes of 14 people consisting of 6 female athletes and 8 male athletes. The data collection tool used is the perception scale of the senior wushu athlete in the exercise program with the validity value of $0.302-0.886$ and the reliability of 0.949 and the achievement motivation scale with the validity value of $0.452-0.873$ and reliablitas 0,962 . Data analysis using Pearson product moment correlation technique. Based on data analysis done by using product moment correlation test, obtained correlation coefficient value ( $r)$ 0,$477 ; p=0,000(p<0,05)$ it means there is positive and significant relation between perception of senior wushu athlete in training program with achievement
\end{abstract}

Email : zawawi@unpkediri.ac.id@2018 UN PGRI Kediri

No Handphone : 08563359083

p-ISSN: 2548-7833

e-ISSN: 2477-3379 
motivation in senior wushu athletes.

Keywords: Perception on exercise program, achievement motivation, wushu athlete.

\section{PENDAHULUAN}

Olahraga wushu beberapa tahun ini merupakan salah satu olahraga yang cepat berkembang di masyarakat, terutama kota besar diseluruh Indonesia. Di Kota Kediri, cabang olahraga wushu mulai masuk pada tahun 2009 di bawah naungan KONI Kota Kediri. Sejak saat itulah prestasi atlet wushu khususnya Sanda atau yang dulu dikenal dengan istilah Sanshou menjadi meningkat secara pesat. Puncak dari peningkatan prestasi adalah pada waktu Pekan Olahraga Provinsi (PORPROV) di Banyuwangi tahun 2015 yang memperoleh total 5 medali emas, perolehan ini naik dibanding dengan PORPROV Madiun tahun 2013 yang memperoleh total 3 medali emas. Keberhasilan para atlet tidak hanya karena mereka digenjot menu latihan yang sangat padat, melainkan juga pembangunan mental yang diberikan oleh pelatih dan official juga bagus dan itu memang dibutuhkan oleh para atlet.

Dalam sebuah pertandingan ataupun turnamen pasti memiliki berbagai macam tekanan baik dari diri atlet maupun dari pelatih. Semua cabang olahraga pasti juga mempunyai cara khusus dalam menangani mental atlet baik dalam latihan maupu bertanding. Ketika mental tidak bagus maka saat bertanding pasti performa atlet juga terganggu. Disamping pembangunan mental yang juga tidak kalah pentingnya adalah terkait dengan menu latihan atau yang biasa disebut dengan program latihan harus diperhatikan betul. Terkait hal tersebut, para atlet juga harus memiliki persepsi yang baik terhadap apa yang ada disekitar mereka saat latihan.

Setiap atlet pasti memiliki hasrat untuk berprestasi. Hasrat tersebut akan ditempuh dengan cara berlatih dengan maksimal. Dengan kata lain, untuk dapat berprestasi diperlukan motivasi. Motivasi sendiri adalah dorongan yang timbul pada diri seseorang, sadar atau tidak sadar untuk melakukan suatu tindakan dengan tujuan tertentu (Pasaribu, 2016). 
Motivasi sebagai proses psikologi adalah refleksi kekuatan interaksi antara kognisi, pengalaman dan kebutuhan (Burstiando, 2015). Motivasi adalah proses yang menjelaskan intensitas, arah, dan ketekunan seorang individu untuk mencapai tujuannya (Mitchell, 2009). Motivasi berprestasi memberikan pengaruh yang besar terhadap pencapaian yang diperoleh seseorang (Haryani \& Tairas, 2014). Hal ini berarti, semakin tinggi motivasi berprestasi seseorang, akan semakin tinggi pula daya juang untuk mencapai tujuan. Dalam hal kegiatan berlatih, motivasi dapat dikatakan sebagai keseluruhan daya penggerak di dalam diri seseorang yang menimbulkan kegiatan berlatih, yang menjamin kelangsungan dari kegiatan latihan, dan memberikan arah pada seseorang yang berlatih agar dapat tercapai.

Motivasi pada dasarnya dapat bersumber pada diri seseorang (motivasi intrinsik) dan dapat pula bersumber dari luar diri seseorang (motivasi ekstrinsik) (Abbas, 2013). Tidak sedikit atlet yang merasa putus asa, kurang percaya diri, dan cepat puas dengan apa yang sudah diraih. Dalam suatu waktu, atlet pasti akan mengalami burnout. Burnout adalah suatu kondisi yang dipenuhi oleh rasa jenuh sehingga banyak energi dan tenaga terbuang sia-sia (Primita \& Wulandari, 2014). Kondisi seperti inilah yang dapat memicu motivasi atlet menurun dan penuruan performa.

Motivasi berprestasi sangat penting, memiliki fungsi sebagai (1) energizer, yaitu motor penggerak yang mendorongindividu melakukan sesuatu, (2) directedness, yaitu menentukan arah perbuatan ke arah yang ingin dicapai, (3) patterning, yakni menyelesaikan perbuatan-perbuatan apa yang harus dikerjakan secara serasi guna mencapai tujuan (McCelland dalam Equata, Yusuf, \& Andayani, 2013).

Pencapaian prestasi tentunya juga di dukung oleh program latihan yang disusun oleh pelatih. Dalam rangka menjaga irama motivasi atlet, pelatih dituntut untuk mendesain program latihan yang menarik. Dengan program latihan yang menarik, atlet akan tetap termotivasi dalam mengikuti latihan, bahkan dapat meningkatkan motivasi berprestasi pada 
diri atlet. Dengan begitu, atlet memiliki persepsi yang positif terhadap program latihan.

Atlet selalu memiliki persepsi terhadap program latihan yang disusun oleh pelatih. Seorang atlet mempersepsikan dirinya terhadap program latihan dipengaruhi oleh pemahaman tentang program latihan. Persepsi sebagai bagian dari proses kehidupan yang dimiliki oleh setiap orang, dari pandangan orang pada titik tertentu, lalu orang tersebut mengkreasikan hal yang dipandangnya untuk dunianya sendiri, kemudian orang tersebut mencoba mengambil keuntungan untuk kepuasannya (Harisah \& Masiming, 2008).

Penelitian Equata et al., (2013) menjelaskan persepsi atlet Taekwondo junior pada program latihan mempengaruhi motivasi berprestasi atlet. Semakin positif persepsi pada program latihan, maka akan semakin tinggi motivasi berprestasi atlet Taekwondo Junior. Penelitian tersebut menunjukkan bahwa persepsi terhadap program latihan mempengaruhi tingkat motivasi berprestasi pada atlet.

Penelitian ini dilakukan untuk mengetahui seberapa besar hubungan persepsi pada program latihan dengan motivasi berprestasi atlet wushu. Penelitian ini akan memberikan pemahaman lain terhadap pelatih untuk memperhatikan komposisi program latihan guna meningkatkan motivasi berprestasi pada diri atlet sehingga presasi maksimal tercapai.

\section{METODE}

Penelitian yang dilaksanakan merupakan penelitian kualitatif dengan metode survei (menggunakan angket). Variabel bebas pada penelitian ini adalah motivasi berprestasi, sedangkan variabel terikatnya adalah persepsi atlet wushu senior pada program latihan. Penelitian ini dilakukan di Kediri yang berpusat pada atlet Puslatkot Cabang Olahraga Wushu Sanda yang akan menghadapi PORPROV tahun 2019 mendatang. Populasi penelitian ini adalah keseluruhan atlet yang tergabung di Puslatkot yang berjumlah 14 atlet. Sampel dalam penelitian ini juga merupakan keseluruhan jumlah populasi. Penelitian ini adalah 
penelitian sampel bukan penelitian populasi karena sampling jenuh adalah teknik penentuan sampel bila semua anggota populasi digunakan sebagai sampel (Sugiyono, 2011).

Hal ini sesuai apa yang dikatakan oleh Arikunto (2002) yang berbunyi, apabila responden kurang dari 100, maka lebih baik diambil semua, sehingga penelitiaannya merupakan penelitian populasi. Dari keseluruhan sampel yang ada di Puslatkot ada 6 atlet putri dan 8 atlet putra.

Pengumpulan data terdiri dari dua sumber data, yaitu primer dan sekunder. Data primer adalah data yang diperoleh dari Pengurus Kota Wushu Kediri yang berkaitan dengan data respon ataupun tanggapan atlet senior Wushu Kota Kediri dari skala motivasi dan skala persepsi atlet pada program latihan. Sedangkan data sekunder adalah data yang diperoleh di lapangan antara lain yaitu observasi, interview dan dokumentasi dari para atlet.

Penelitain yang dilaksanakan ini menggunakan dua macam skala yang diadaptasi dan sudah dimodifikasi oleh peneliti , yakni skala motivasi dan skala persepsi atlet wushu senior pada program latihan. Kedua skala tersebut dipisahkan menjadi pernyataan Favourable dan pernyataan Unfavourable. Sistem scoring dalam skala penilaian ini menggunakan Likert (Azwar, 2007) yang sudah dimodifikasi dengan 4 alternatif jawaban yaitu : Sangat Sesuai (SS), Sesuai (S), Tidak Sesuai (TS) dan Sangat Tidak Sesuai (STS).

Tabel 1. Penilaian Pernyataan

\begin{tabular}{lcc}
\hline Kategori Jawaban & Favouable & Unfavourable \\
\hline Sangat Sesuai & 4 & 1 \\
\hline Sesuai & 3 & 2 \\
\hline Tidak Sesuai & 2 & 3 \\
\hline Sangat Tidak Sesuai & 1 & 4
\end{tabular}

(Azwar, 2007) 


\section{HASIL DAN PEMBAHASAN}

\section{Hasil}

\section{Uji Asumsi Dasar}

\section{a. Uji Normalitas}

Uji normalitas adalah suatu prosedur yang digunakan untuk mengetahui apakah data berasal dari populasi yang terdistribusi normal atau berada dalam sebaran normal (Hanief \& Himawanto, 2017). Data yang diuji adalah sebaran data skala motivasi berprestasi dan skala persepsi atlet wushu Sanda pada program latihan. Pengujian menggunakan One Kolmogorov Smirnov Test dengan bantuan SPSS versi 21. Berikut hasil analisi data untuk uji normalitas:

Tabel 2. Hasil Uji Normalitas

One-Sample Kolomogorov-Smirnov Test

\begin{tabular}{llcc}
\hline \multicolumn{1}{c}{$\mathrm{N}$} & & $y$ & $x$ \\
\hline Normal Parameters $^{\mathrm{a}}$ & & 14 & 14 \\
\hline & Mean & 86.75 & 88.04 \\
\hline Most Extreme & Std. Deviation & 8.231 & 8.722 \\
\hline Differences & Absolute & .120 & .132 \\
\hline & Positive & .120 & .086 \\
\hline Kolomogorov-Smirnov Z & Negative & -.082 & -.119 \\
\hline Asymp. Sig. (2-tailed) & & .921 & .975 \\
\hline
\end{tabular}

a. Test distribution is Normal

Keterangan:

$\mathrm{Y}=$ Motivasi berprestasi

$\mathrm{X}=$ Persepsi atlet wushu pada program latihan

Berdasarkan hasil uji normalitas pada tabel 2 dapat diketahui nilai Signifikansi pada variabel $Y=$ motivasi berprestasi, yaitu sebesar 0,300 $(p>0,05)$. Sedangkan nilai signifikansi pada variabel $X=$ persepsi atlet wushu pada program latihan, yaitu sebesar 0,269 ( $p>0,05)$. Sehingga dapat disimpulkan kedua variabel berdistribusi normal.

\section{b. Uji Linieritas}

Uji linieritas adalah suatu prosedur yang digunakan untuk mengetahui status linier tidaknya suatu distribusi data penelitian. Uji linieritas dilakukan untuk membuktikan bahwa masing-masing variabel 
bebas mempunyai hubungan yang linier dengan variabel terikat (Hanief \& Himawanto, 2017).

Uji linieritas dalam penelitian ini menggunakan test for linierity dengan bantuan SPSS versi 21. Hasil uji linieritas ditunjukkan pada tabel 3 berikut:

Tabel 3. Hasil Uji Linieritas

\begin{tabular}{|c|c|c|c|c|c|c|c|}
\hline & & & $\begin{array}{l}\text { Sum of } \\
\text { Square }\end{array}$ & $\overline{d f}$ & $\begin{array}{l}\text { Mean } \\
\text { Square }\end{array}$ & $F$ & Sig. \\
\hline \multirow[t]{5}{*}{$Y^{*} X$} & $\begin{array}{l}\text { Between } \\
\text { Groups }\end{array}$ & (Combined) & 1843.342 & 7 & 263.335 & 2.221 & .092 \\
\hline & & Linearity & 553.287 & 1 & 553.287 & 23.932 & .000 \\
\hline & & $\begin{array}{l}\text { Deviation } \\
\text { from } \\
\text { Linearity }\end{array}$ & 665.123 & 6 & 110.853 & .844 & 0.321 \\
\hline & $\begin{array}{l}\text { Within } \\
\text { Groups }\end{array}$ & & 1021.466 & 4 & 255.367 & & \\
\hline & Total & & 2239.876 & 14 & & & \\
\hline
\end{tabular}

Keterangan:

$\mathrm{Y}=$ Motivasi berprestasi

$\mathrm{X}=$ Persepsi atlet wushu pada program latihan

Berdasarkan hasil uji linieritas pada tabel 3 dapat diketahui nilai Signifikansi pada kolom linierity sebesar $0,000(p<0,05)$. Hal ini berarti hubungan antara kedua variabel bersifat linier.

\section{Uji Hipotesis}

Uji hipotesis dalam penelitian ini menggunakan korelasi Product Moment by Pearson untuk mengetahui tingkat korelasi atau hubungan antara dua variabel dan untuk mengetahui arah hubungan variabel. Hasil uji hipotesis ditunjukkan pada tabel 4 berikut:

Tabel 4. Hasil Analisis Korelasi Product Moment by Pearson

\begin{tabular}{|c|c|c|c|}
\hline & & $\mathrm{y}$ & $\mathrm{x}$ \\
\hline \multirow{3}{*}{$y$} & Pearson Correlation & 1 & $.477^{\star \star}$ \\
\hline & Sig. (2-tailed) & & .000 \\
\hline & $\mathrm{N}$ & 14 & 14 \\
\hline \multirow[t]{3}{*}{$x$} & Pearson Correlation & $.477^{* *}$ & \\
\hline & Sig. (2-tailed) & .000 & \\
\hline & $\mathrm{N}$ & 14 & 14 \\
\hline
\end{tabular}

Keterangan:

$\mathrm{Y}=$ Motivasi berprestasi 
$X=$ Persepsi atlet wushu pada program latihan

Berdasarkan hasil analisis data pada tabel 4 dapat diketahui besarnya koefisien korelasi antara variabel motivasi berprestasi dengan persepsi atlet wushu pada program latihan sebesar 0,477 dengan nilai Sig. sebesar 0,000 $(p<0,05)$. Hal ini berarti ada hubungan positif antara persepsi atlet wushu pada program latihan dengan motivasi berprestasi. Nilai $r$ positif $(+)$ menunjukkan bahwa semakin tinggi variabel persepsi atlet wushu pada program latihan maka akan semakin tinggi pula variabel motivasi berprestasi.

\section{Kontribusi Persepsi Atlet Wushu Senior pada Program Latihan terhadap Motivasi Berprestasi}

Tingkat kontribusi atlet wushu senior pada program latihan terhadap motivasi berprestasi dapat diketahui dengan melihat koefisien determinan, yakni $R^{2}$ ( $R$ Square). Nilai $R^{2}$ yang dicari dengan menggunakan bantuan SPSS versi 21, dan menghasilkan angka 0,421, atau dapat dikatakan bahwa kontribusi atlet wushu senior pada program latihan terhadap motivasi berprestasi adalah sebesar 42,1\%. Adapun tabelnya dibawah ini :

Tabel 5. Measures Association

\begin{tabular}{lllll}
\hline & $\mathrm{R}$ & $\mathrm{R}$ & Eta & Eta Squared \\
& \multicolumn{5}{c}{ Squared } & \\
\hline $\mathrm{y}^{*} \mathrm{x}$ & .477 & .421 & .650 & .554 \\
\hline
\end{tabular}

\section{a. Analisis Deskriptif}

Analisis Deskriptif disini dimaksudkan untuk memberikan gambaran umum mengenai kondisi persepsi atlet wushu senior pada program latihan dan motivasi berprestasi pada subjek yang diteliti. Selain tujuan tersebut analisis deskriptif juga dimaksudkan untuk memberikan gambaran tentang ringasan data penelitian. Berikut ini disajikan deskripsi data penelitian serta subjek penelitian: 
Tabel 6. Deskripsi Hasil Penelitian

\begin{tabular}{|c|c|c|c|c|c|c|c|c|c|}
\hline \multirow[b]{2}{*}{ Skala } & \multirow{2}{*}{$\begin{array}{l}\text { Jml. } \\
\text { Subjek }\end{array}$} & \multicolumn{2}{|c|}{$\begin{array}{l}\text { Data } \\
\text { Hipotetik }\end{array}$} & \multirow[b]{2}{*}{ M } & \multirow[b]{2}{*}{ SD } & \multicolumn{2}{|c|}{ Data Empirik } & \multirow[b]{2}{*}{ M } & \multirow[b]{2}{*}{ SD } \\
\hline & & $\begin{array}{l}\text { Hilp } \\
\text { Skor } \\
\text { Min }\end{array}$ & $\begin{array}{l}\text { SellK } \\
\text { Skor } \\
\text { Maks }\end{array}$ & & & $\begin{array}{l}\text { Skor } \\
\text { Min }\end{array}$ & $\begin{array}{l}\text { Skor } \\
\text { Maks }\end{array}$ & & \\
\hline$y$ & 14 & 30 & 120 & 75 & 15 & 69 & 117 & 86,75 & 8,231 \\
\hline$x$ & 14 & 30 & 120 & 75 & 15 & 63 & 118 & 88,04 & 8,722 \\
\hline
\end{tabular}

Keterangan:

Jml : Jumlah

Min : Minimal

Maks : Maksimal

M : Mean

SD : Standar Deviasi

y : Motivasi Berprestasi

$\mathrm{x} \quad$ : Persepsi Atlet Wushu Senior pada Program Latihan

Selanjutnya akan dilakukan pengkategorian. Tujuannya adalah untuk mengetahui secara detail berapa frekuensi subyek menempati masing-masing kategori. Tabel kategori disusun berdasarkan skala penelitian.

Tabel 7. Kategori Persepsi pada Program Latihan dengan Motivasi Berprestasi

\begin{tabular}{ccccc}
\hline Variabel & Kategori & Skor & Jumlah & Porsentase \\
\hline \multirow{3}{*}{$y$} & Tinggi & $X \geq 90$ & 10 & $72 \%$ \\
\cline { 2 - 5 } & Sedang & $60 \leq X<90$ & 4 & $28 \%$ \\
\cline { 2 - 5 } & Rendah & $X<60$ & 0 & $0 \%$ \\
\hline \multirow{3}{*}{$x$} & Tinggi & $X \geq 90$ & 12 & $85 \%$ \\
\cline { 2 - 5 } & Sedang & $60 \leq X<90$ & 2 & $15 \%$ \\
\cline { 2 - 5 } & Rendah & $X<60$ & 0 & $0 \%$ \\
\hline
\end{tabular}

Keterangan:

y : Motivasi Berprestasi

$\mathrm{x} \quad$ : Persepsi Atlet Wushu Senior pada Program Latihan

Berdasarkan pengkategorian pada tabel 7 menunjukkan bahwa sebanyak 10 atlet memiliki motivasi berprestasi yang tinggi, sementara 4 atlet memiliki motivasi berprestasi yang sedang. 12 dari 14 atlet memiliki persepsi pada program latihan dengan kategori tinggi, sisanya sedang. Jika digambarkan dalam grafik sebagai berikut: 


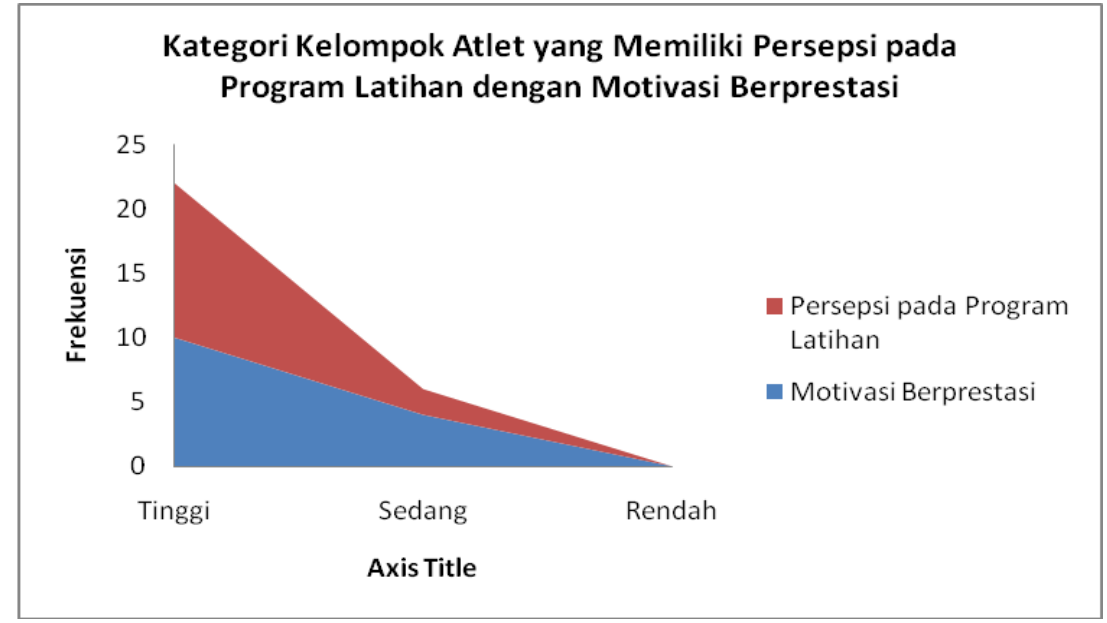

Gambar 1. Kategori Kelompok Atlet yang Memiliki Persepsi pada Program Latihan dengan Motivasi Berprestasi

\section{Pembahasan}

Hasil yang diperoleh dari uji hipotesis telah menunjukan bahwa diterimanya hipotesis yang diajukan yaitu hubungan positif yang signifikan antara persepsi atlet wushu senior pada program latihan terhadap motivasi berprestasi pada atlet wushu Kota Kediri. Persepsi atlet pada program latihan dipengaruhi oleh banyak faktor. Salah satunya adalah komposisi program latihan tersebut. Selain penyusunan program latihan secara baik juga harus mengandung unsure untuk meningkatkan motivasi para atlet, bukan malah menurunkan motivasi para atlet. Menyusun program latihan merupakan kompetensi terpenting bagi seorang pelatih (Wijanarko, 2009). Program latihan yang disusun tidak hanya untuk meningkatkan kemampuan atlet, lebih dari itu ada beberapa fungsi. Gunarsa (2008) menjelaskan fungsi program latihan. Pertama, program latihan harus memiliki tujuan dan sasaran yang jelas atau goal setting, artinya program latihan yang telah disusun benar-benar untuk meningkatkan suatu kemampuan tertentu, melalui isi dari program latihan tersebut. Kedua, program latihan harus menerapkan prinsip peningkatan (progressive principle), artinya program latihan memiliki dampak perubahan yang lebih baik dari sebelumnya. Ketiga, harus memiliki konsep variasi agar atlet tidak jenuh dalam mengikuti latihan. Keempat, program latihan harus memberikan perhatian khusus pada faktor 
keberhasilan dan kegagalan. Dalam latihan perlu adanya daya pendorong dalam pencapaian prestasi, hal ini dapat melalui rekan berlatih. Rekan berlatih yang telah berhasil dalam pencapaian prestasi, harus dimanfaatkan oleh pelatih untuk mendorong atlet lain yang belum mampu mencapai prestasi secara maksimal. Kelima, pengadaan catatan pribadi atau personal data record. Catatan tersebut membantu pelatih maupun atlet untuk mengambil tindakan atas setiap evaluasi.

Peran persepsi atlet wushu pada program latihan menunjang keberhasilan sekaligus motivasi berprestasi atlet itu sendiri. Hal ini sesuai dengan penelitian yang dilakukan oleh Nisa' (2017) menyebutkan bahwa Sasana wushu sanda Kota Kediri memiliki progam latihan yang disusun oleh pelatih. Program yang dibuat adalah program harian, mingguan, dan bulanan. Latihan dilakukan seminggu 2 kali, dan jika sudah masuk training centre (TC) bisa dilakukan 6 kali dalam seminggu dengan waktu efektif setiap kali latihan 2 jam di lapangan yang diberikan dengan materi latihan fisik, teknik dan taktik. Latihan fisik tidak ditangani oleh pelatih khusus fisik, melainkan sekaligus diberikan pelatih teknik yang dibantu oleh asisten pelatih. Dan disamping itu divariasikan dengan games agar atlet tidak terlalu tegang.

Penyusunan program latihan di Sasana wushu sanda Kota Kediri memberikan persepsi yang baik bagi para atletnya. Hal ini sesuai dengan hasil penelitian bahwa 10 dari 14 atlet memiliki persepsi pada program latihan dengan kategori tinggi. Dampaknya pun berpengaruh pada motivasi berprestasi, yang ditunjukkan oleh porsentase sebesar $72 \%$ atlet memiliki motivasi berprestasi tinggi.

Penelitian ini menjelaskan bahwa ada hubungan yang signifikan antara persepsi atlet wushu pada program latihan dengan motivasi berprestasi. Penelitian ini diperkuat oleh hasil penelitian yang dilakukan oleh Equata et al., (2013) bahwa ada hubungan positif yang signifikan antara persepsi atlet taekwondo junior pada program latihan dengan motivasi berprestasi pada atlet taekwondo junior. Program latihan yang baik akan meningkatkan motivasi berprestasi pada atlet. Sehingga 
penelitian ini diharapkan mampu memberikan pengetahuan terhadap pelatih bahwa pencapaian prestasi dimulai dari penyusunan program latihan yang baik.

\section{KESIMPULAN DAN SARAN}

Persepsi atlet wushu senior pada program latihan berhubungan secara signifikan dengan motivasi berprestasi. Atlet yang memiliki persepsi baik pada program latihan juga memiliki motivasi berprestasi yang baik pula, begitu juga sebaliknya.

Para pelatih disarankan supaya mengemas program latihan yang baik, menarik dan efektif dalam meningkatkan motivasi berprestasi pada diri atlet.

\section{DAFTAR PUSTAKA}

Abbas, Y. (2013). Motivasi Intrinsik, Motivasi Ekstrinsik, Kompetensi dan Kinerja Guru. Humanitas, 10(1), 61-74.

Arikunto, S. (2010). Prosedur Penelitian Suatu Pendekatan Praktik. Jakarta : PT. Rineka Cipta.

Azwar, S. (2007). Metode Penelitian. Yogyakarta: Pustaka Pelajar.

Burstiando, R. (2015). Jurnal Sportif. Jurnal SPORTIF : Jurnal Penelitian Pembelajaran (Vol. 1). Universitas Nusantara PGRI Kediri. Retrieved from http://ojs.unpkediri.ac.id/index.php/pjk/article/view/571.

Equata, Z. K., Yusuf, M., \& Andayani, T. R. (2013). Hubungan antara Persepsi Atlet Taekwondo Junior pada Program Latihan dengan Motivasi Berprestasi. Jurnal Ilmiah Psikologi Candrajiwa, 1(4). Retrieved from http://candrajiwa.psikologi.fk.uns.ac.id/index.php/candrajiwa/article/ view/36/28.

Gunarsa, S. D. (2008). Psikologi Olahraga Prestasi. Jakarta: PT. BPK Gunung Mulia.

Hanief, Y. N., \& Himawanto, W. (2017). Statistik Pendidikan. Yogyakarta: Deepublish.

Harisah, A., \& Masiming, Z. (2008). Persepsi Manusia Terhadap Tanda,Simbol Dan Spasial. Jurnal SMARTek, 6(1), 29-43.

Haryani, R., \& Tairas, M. M. W. (2014). Motivasi Berprestasi Pada 
Mahasiswa Berprestasi dari Keluarga Tidak Mampu Secara Ekonomi. JURNAL Psikologi Pendidikan Dan Perkembangan, 3(1), 30-36.

Mitchell, T. R. (2009). Research in Organizational Behavior. New York: McGraw - Hill Irwin.

Nisa', W. (2017). Perkembangan Prestasi Sasana Wushu Sanda Kota Kediri Dalam Event Porprov Jatim. Skripsi. Tidak diterbitkan. Universitas Nusantara PGRI Kediri: Kediri.

Pasaribu, A. M. N. (2016). Jurnal Sportif. Jurnal SPORTIF: Jurnal Penelitian Pembelajaran (Vol. 2). Universitas Nusantara PGRI Kediri. Retrieved from http://ojs.unpkediri.ac.id/index.php/pjk/article/view/510.

Primita, H. Y., \& Wulandari, D. A. (2014). Hubungan Antara Motivasi Berprestasi Dengan Burnout Pada Atlet Bulutangkis Di Purwokerto. PSYCHO IDEA, 12(1), 10-18.

Sugiyono. (2011). Metode Penelitian Kuantitatif, Kualitatif dan R\&D. Bandung: Alfabeta.

Wijanarko, B. (2009). Teori Perencanaan Program Latihan. Surakarta: Universitas Sebelas Maret Press. 